\title{
Transient Receptor Potential Ankyrin 1 Channel: An Evolutionarily Tuned Thermosensor
}

\author{
Viktor SINICA ${ }^{1}$, Viktorie VLACHOVÁ ${ }^{1}$ \\ ${ }^{1}$ Laboratory of Cellular Neurophysiology, Institute of Physiology of the Czech Academy of \\ Sciences, Czech Republic
}

Received April 7, 2021

Accepted May 26, 2021

Epub Ahead of Print May 12, 2021

\section{Summary}

The discovery of the role of the transient receptor potential ankyrin 1 (TRPA1) channel as a polymodal detector of cold and pain-producing stimuli almost two decades ago catalyzed the consequent identification of various vertebrate and invertebrate orthologues. In different species, the role of TRPA1 has been implicated in numerous physiological functions, indicating that the molecular structure of the channel exhibits evolutionary flexibility. Until very recently, information about the critical elements of the temperature-sensing molecular machinery of thermosensitive ion channels such as TRPA1 had lagged far behind information obtained from mutational and functional analysis. Current developments in single-particle cryo-electron microscopy are revealing precisely how the thermosensitive channels operate, how they might be targeted with drugs, and at which sites they can be critically regulated by membrane lipids. This means that it is now possible to resolve a huge number of very important pharmacological, biophysical and physiological questions in a way we have never had before. In this review, we aim at providing some of the recent knowledge on the molecular mechanisms underlying the temperature sensitivity of TRPA1. We also demonstrate how the search for differences in temperature and chemical sensitivity between human and mouse TRPA1 orthologues can be a useful approach to identifying important domains with a key role in channel activation.

\section{Key words}

Transient Receptor Potential Ankyrin 1 - Structure-function • Noxious heat • Noxious cold • Functional diversity • Gating models

\section{Corresponding author}

V. Sinica and V. Vlachová, Laboratory of Cellular Neurophysiology, Institute of Physiology of the Czech Academy of Sciences, Videnska 1083, 14220 Prague 4, Czech Republic. E-mail: viktor.sinica@img.cas.cz or Viktorie.Vlachova@fgu.cas.cz

\section{Introduction}

The transient receptor potential (TRP) superfamily of receptors belongs to a large group of tetrameric nonselective cation channels. According to their amino acid sequence homology, the TRP channels are divided into seven subfamilies: TRPC (Canonical), TRPV (Vanilloid), TRPM (Melastatin), TRPP (Polycystin, also known as PKD), TRPML (Mucolipin), TRPA (Ankyrin), and TRPN (No mechanoreceptor potential $\mathrm{C}$, also known as NOMPC). The TRPA1 channel is expressed in various organs and tissues, where it serves mainly as a universal, nociception-mediating cellular sensor activated by various environmental irritants, potentially harmful physical modalities and endogenous mediators of pathophysiological processes (reviewed in (Dai 2016, Talavera et al. 2020)). TRPA1 transduces these stimuli into the opening of the channel and influx of cations into the cell. In free nerve endings, such a cation influx locally depolarizes the membrane and triggers the resting sodium channels, evoking the action potential. In addition, TRPA1 channels permeate calcium ions that serve as intracellular messengers and modulators, triggering cellular pathways and modulating the activity of the channel. TRPA1 is involved in the 
processes of inflammation (Bandell et al. 2004, Bautista et al. 2006), migraine (Marone et al. 2018), diabetes (Wei et al. 2010), neuropathic pain (Nativi et al. 2013), itching (Wilson et al. 2013) and mechanic allodynia in anticancer drug treatment (Nassini et al. 2011), therefore it is a tempting target for novel analgesic and antiinflammatory molecules. However, the polymodal and allosteric nature of TRPA1 should be kept in mind in order to specifically target the unwanted properties of TRPA1 modulation (e.g. cold allodynia and hyperalgesia as a side-effect of anti-cancer drugs), while preserving the useful ones (e.g. sensory response to irritant compounds and noxious cold).

The properties of TRPA1 are strongly speciesspecific and diverse. Therefore, some TRPA1 orthologues exhibit activation by both cold and heat (reviewed in (Hoffstaetter et al. 2018)). The mechanisms underlying such bimodal effects of temperature are not yet fully understood. In addition, temperature activation is modulated by voltage and various chemical stimuli, indicating an allosteric nature of TRPA1 gating. This review aims to summarize the findings about the temperature modulation of TRPA1 across the TRPA1 orthologues of various species and the related thermosensitive TRP channels. These findings will be combined with the insights into the structural and molecular context to elucidate the allosteric nature and the mechanisms of the polymodal regulation of TRPA1.

\section{The structure of the TRPA1 channel}

So far, five studies have been published that reveal the structure of the TRPA1 channel with the use of cryo-electron microscopy (cryo-EM) at a resolution below $5 \AA$ (Paulsen et al. 2015, Liu et al. 2020, Suo et al. 2020, Terret et al. 2021). TRPA1 shares the topology of the transmembrane domain (TMD) with all other members of the TRP ion channel family - it is composed of the voltage sensing-like domain (VSLD) assembled from helices S1-S4, C-terminal TRP-like domain (TRPL), and a pore domain (PD) containing helices S5-S6 and the pore loop with the selective filter and two pore helices (Fig. 1). The VSLD and PD are connected by the S4-S5 linker. The $\mathrm{N}$-terminus is characterized by a feature shared with TRPV, TRPN and TRPC channels - the presence of ankyrin repeats (ARs), 33-residue motifs consisting of pairs of antiparallel $\alpha$-helices connected by $\beta$-hairpin motifs. The ankyrin repeat domain (ARD) of TRPA1 consists of a tandem array of 16 ARs. The N-terminus is connected to the TMD through the coupling domain (CD) that contains the TRPA1-specific binding site for pungent electrophilic compounds. The C-terminus includes similar structural elements to the TRPM and TRPC channels - the coiled-coil (CC) domain and the interfacial helix (IFH), and similar to TRPV channels - a three-stranded $\beta$-sheet. To date, in total 28 mammalian TRP channels have been identified and around 136 cryo-electron microscopy TRP structures have been determined at high resolution (Huffer et al. 2020), enabling us to discover the general mechanisms of TRP activation and regulation, as well as the specific features of each channel.

\section{Species differences in the chemical sensitivity of TRPA1}

Phylogenetic analyses of TRPA1 orthologues show that the TRPA1 clade diversified from the TRPA branch 500 million years ago as a chemosensory receptor for electrophilic compounds that evoke pungent and irritating sensations (Kang et al. 2010). The electrophilic agonists also include intracellular mediators of oxidative stress and inflammation, highlighting the TRPA1 channel as an important component of the defensive cellular system (Viana 2016). Therefore, the activation of TRPA1 by electrophiles is present in all animal classes, including insects, fish, amphibians, reptilians, avians, and mammals (as reviewed in (Chen and Kym 2009, Bianchi et al. 2012, Laursen et al. 2014)). On the other hand, noncovalent modulators mostly exhibit species-dependent bimodal action, i.e. activation at lower concentrations, but also inhibition at higher concentrations. This includes divergent effects of non-covalent modulators such as caffeine (Nagatomo and Kubo 2008), menthol (Xiao et al. 2008) or nicotine (Talavera et al. 2009) on TRPA1 orthologues. Typical non-covalent activators are natural odorants and repellents from essential oils, therefore the shift of the non-covalent modulators may be strongly related to the environmental adaptation according to the food intake and its accessibility (Startek et al. 2019b). The cause of this evolutionary adaptation lies in the primary structure of TRPA1 orthologues and, consequently, in alterations of their non-covalent binding sites of TRPA1 that finely tune TRPA1's properties. The comparison of TRPA1 orthologues together with the functional characterization of wild types and chimeric constructs resulted in the localization of the binding sites for caffeine (Nagatomo and Kubo 2008) and menthol (Karashima et al. 2007), but also for the synthesized 
selective TRPA1 inhibitors HC-030031 (Gupta et al. 2016) and A-967079 (Chen et al. 2011).

TRPA1-mediated detection can be attenuated by cellular mechanisms that affect the excitability of the nociceptive neurons. For example, Highveld naked molerats developed a complete loss of TRPA1-mediated pain responses in the presence of the electrophilic agonist allyl isothiocyanate (AITC) due to the overexpression of a voltage- insensitive leak channel (NALCN) (Smith et al. 2020). It is believed that in this way, the Highveld mole-rats specifically were able to overcome the presence of the aggressive Natal droptail ants, whose toxic venom evokes strong pain-related behavior by the blockage of NALCN channels (Eigenbrod et al. 2019).
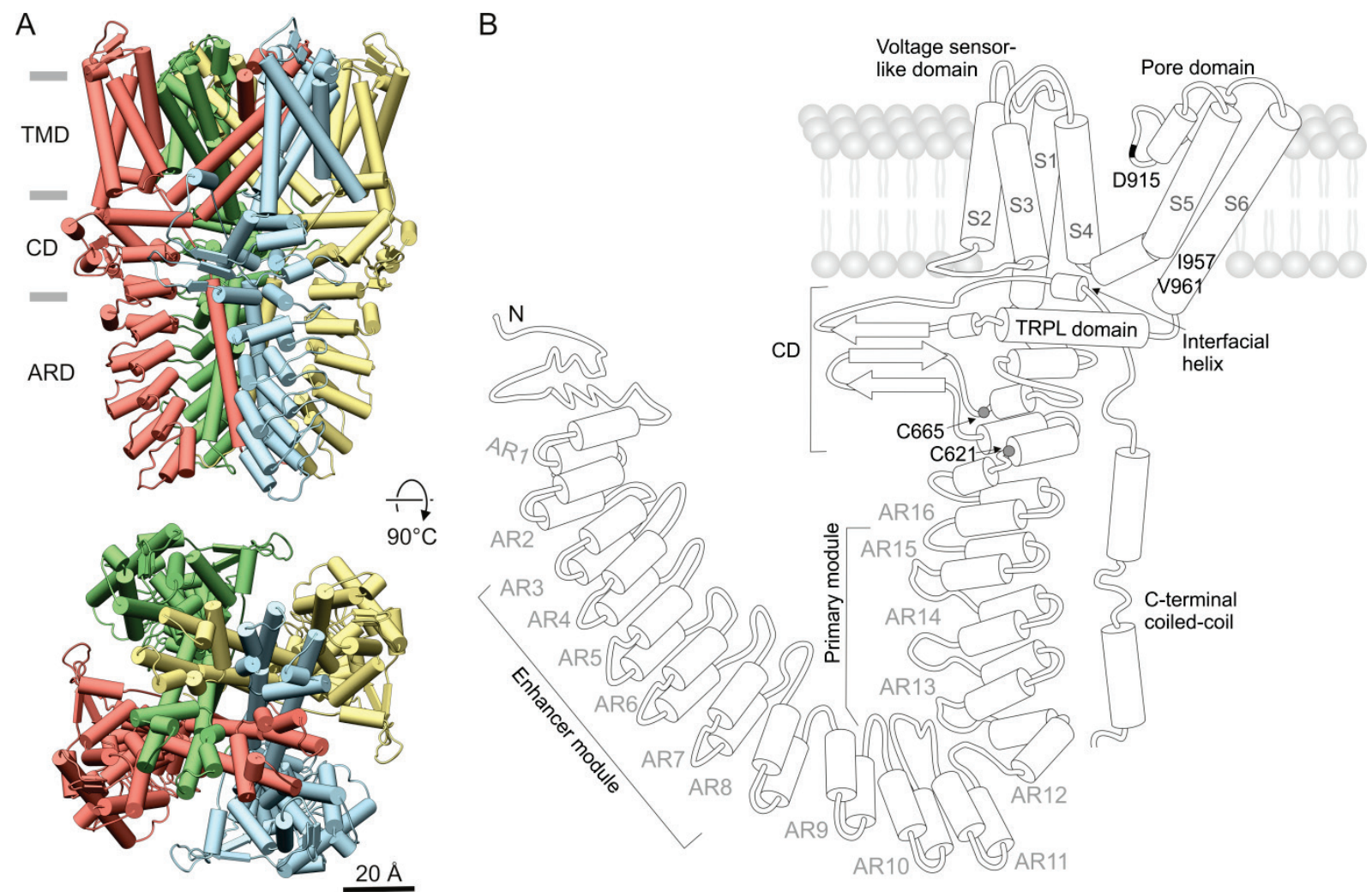

Fig. 1. The topology overview of the human TRPA1 channel. (A) The overall architecture of the TRPA1 tetramer (Protein Databank, PDB, ID: 6PQO) represented as pipes and planks. Four subunits colored by chain are shown from the side and the top. TMD, transmembrane domain, $C D$, coupling domain, $A R D$, ankyrin repeat domain. (B) A single TRPA1 protomer with indicated domains: ARD formed by ankyrin repeats AR1-AR16. Two functionally distinct modules of ARD are indicated. Transmembrane segments S1-S6, voltage sensor-like domain formed by S1-S4, the pore domain (S5-S6 region) with the upper gate formed by D915, and the lower gate formed by hydrophobic residues I957 and V961. The TRP-like domain is a conserved site of allosteric modulation. Within the coupling domain (CD), two reactive cysteine residues (C621 and C665) important for electrophile activation are indicated.

\section{Species differences in the temperature sensitivity of TRPA1}

In addition to chemosensitivity, TRPA1 orthologues can also serve as sensors of noxious or warm temperatures (reviewed in (Saito and Tominaga 2017, Hoffstaetter et al. 2018, Talavera et al. 2020)). Species tune the temperature sensor properties of TRPA1 to utilize them in the detection of noxious temperature (Saito et al. 2012), maintenance of optimal core and environmental temperatures (Saito et al. 2019) and in the detection of infrared radiation (Gracheva et al. 2011). In Drosophila melanogaster, the TRPA1 channel was first distinguished as a receptor for electrophilic compounds and heat above $26^{\circ} \mathrm{C}$ (Hamada et al. 2008, Kang et al. 2010). The properties of the Drosophila TRPA1 orthologues (dTRPA1) are tuned by the alternative tissuespecific splicing, resulting in four TRPA1 isoforms (dTRPA1-A, B, C, D) (Kang et al. 2011, Zhong et al. 2012). Isoforms dTRPA1-A and dTRPA1-B are expressed in central brain neurons and detect heat at low thresholds and at rapid rates (Kang et al. 2011, Luo et al. 2017), triggering precautious behavior and maintaining optimal temperature (Hamada et al. 2008). The dTRPA1-A isoform is also expressed in the chemosensors of a proboscis, where it acts as 
a chemosensor thanks to its reduced thermosensitivity (Kang et al. 2011). The other two isoforms, dTRPA1-C and dTRPA1-D, are expressed in polymodal nociceptors as receptors of noxious conditions (Zhong et al. 2012). Although both isoforms are activated by electrophiles and increased temperature, their in vivo role is split: dTRPA1-C is a UV-nociceptor and detector of electrophiles, whereas dTRPA1-D acts as a noxious thermosensor ( $\mathrm{Gu}$ et al. 2019). Apart from TRPA1, Drosophila also has other members of the TRPA family, Painless and Pyrexia, with their own isoforms. Both channels are involved in the detection of noxious heat (Hwang et al. 2012). Mosquitos have also tuned the properties of their TRPA1 isoforms (AgTRPA1) to match their needs. The AgTRPA1-A isoform is used for hostseeking thermotaxis, whereas AgTRPA1-B with similar electrophilic affinity but a higher temperature threshold is used for the detection of noxious temperatures (Kang et al. 2011). The role of the TRPAl channel in the maintenance of optimal temperature is also considered in eusocial insects, such as honeybees (Apis Mellifera). The honeybee TRPA1 channels have a heat threshold of $34{ }^{\circ} \mathrm{C}$ in order to maintain the proper temperature of the nest for the larvae and to induce nest-cooling behavior in time (Kohno et al. 2010).

The approach of tuning the effect of TRPA1 channels by the presence of several forms was also evolutionarily selected in zebrafish (Danio Rerio) with two TRPA1 paralogs, zTRPAla and zTRPAlb. Experiments on zebrafish with knocked-down Trpala and/or Trpalb genes retained its behavioral response to both heat and cold thermal stimuli, suggesting that zTRPA1 paralogues do not contribute to the nociception in vivo and that there are some other channels that adopt the thermal nociception (Prober et al. 2008). The related TRPV1 channel that accompanies zTRPA1b in the peripheral nerve endings is used for heat nociception (Gau et al. 2013). In addition, zebrafish lack the TRPM8 channel, which is widely used across species in the detection of noxious cold (Kastenhuber et al. 2013). Potentially, the loss of zTRPA1 channels might be compensated by the presence of another cold-activated channels, such as TRPC5 channel (Von Niederhausern et al. 2013). The electrophysiological measurements on Xenopus oocytes transiently expressing one of the zTRPA1 paralogues showed the separation of their functions - zTRPAla acts as the chemical sensor, while zTRPA1b covers activation by warming above $25^{\circ} \mathrm{C}$ with no clear threshold and, surprisingly, activation by cooling below $10{ }^{\circ} \mathrm{C}$ (Oda et al. 2016). These bimodal thermal properties were also found for a TRPA1 orthologue of the pufferfish (Oda et al. 2018), but not for the medaka fish orthologue, which only exhibited the heat activation (Oda et al. 2017).

In the western clawed frog and the green anole, the heat thresholds of TRPA1 orthologues $\left(39.7^{\circ} \mathrm{C}\right.$ and $34{ }^{\circ} \mathrm{C}$, respectively) match the thermal preferences of the species (Saito et al. 2012). Adaptation to the different thermal conditions in two Хenopus species is accomplished by functional shifts of the thermal thresholds of TRPA1 and TRPV1 channels (Saito et al. 2016). A comparison of the functional properties of TRPA1 orthologues of four closely related Xenopus species living in different temperature niches showed that the changes in the TRPA1 activity rather than sensitivity to heat contributes to the evolutionary thermal adaptation (Saito et al. 2019). Likewise, the sun-dwelling anole lizard species have a significantly increased temperature threshold of their behavioral and TRPA1-mediated responses than the shade-dwelling species (Akashi et al. 2018). These findings highlight the importance of thermal sensors in environmental adaptation.

Radiation-detecting snakes have evolved a pit organ that contains a pit membrane innervated with trigeminal ganglion (TG) neurons that serves as a passive antenna for radiant heat. The pit-bearing snakes (rattlesnake, python, boa) have evolutionarily selected the TRPA1 channel to transduce the heating from the pitorgan into neural activity (Gracheva et al. 2010, Geng et al. 2011). TRPA1 orthologues of these pit-bearing snakes exhibit robust and steep responses to heat (with a threshold of $27.6^{\circ} \mathrm{C}, 32.7^{\circ} \mathrm{C}$ and $29.6{ }^{\circ} \mathrm{C}$, respectively) (Gracheva et al. 2010). A positive correlation between the thermal sensitivity and the current peak amplitude was observed in the rattlesnake and boa snake, where the relationship was steeper in the rattlesnake orthologue (Kang 2016). This relationship could be explained by the influx of cytosolic calcium ions that potentiate both TRPA1 orthologues to a different extent (Du and Kang 2020). A total number of 47 candidate genes related to the infrared perception in snakes were identified; the molecular mechanisms underlying their infrared perception might soon be elucidated (Tu et al. 2020).

TRPA1 as a noxious heat and chemical sensor is expressed in vertebrates together with TRPV1 (Story et al. 2003). The diversity in TRPA1-positive neuronal sensitization is also accounted for by coexpression and heteromerization with TRPV1 (Patil et al. 2020). The 
conservation of TRPV1 heat sensitivity throughout vertebrate evolution could have changed functional constraints on TRPA1 and influenced the functional evolution of TRPA1 in terms of temperature sensitivity, while conserving its noxious chemical sensitivity (Saito et al. 2012, Saito and Tominaga 2017). While TRPA1 is a radiant heat sensor of snakes possessing pit organs (Gracheva et al. 2010), the ganglion-specific splicing of TRPV1 has an analogous function in the infrared sensing of vampire bats (Gracheva et al. 2011).

\section{Temperature activation of mammalian TRPA1 channels}

In mammals, there is only a single gene encoding the TRPA1 channel. The mouse TRPA1 channel exists in dorsal root ganglia (DRG) in two isoforms, TRPA1a and TRPA1b. However, the TRPA1b isoform lacks the transmembrane region and is nonfunctional as a channel, and was shown to interact with TRPA1a to enhance its surface expression (Zhou et al. 2013). TRPA1 was first recognized in 2003 as a cold receptor in mammals (Story et al. 2003). Its activation by cold temperatures is still a matter of debate, as the recent studies provide evidence either supporting (Story et al. 2003, Sawada et al. 2007, Karashima et al. 2009, del Camino et al. 2010) or denying (Jordt et al. 2004, Knowlton et al. 2010, Cordero-Morales et al. 2011, Chen et al. 2013) the activation of TRPA1 by cold or its involvement in cold perception. Rodent TRPA1 is activated by lowering the temperature to $10^{\circ} \mathrm{C}$, both when transiently expressed and in DRG neuronal culture (Bandell et al. 2004, del Camino et al. 2010). Cold increases the channel's open probability, slightly decreases the unitary conductance and creates a leftward shift of the half-maximal activation voltage $V_{50}$ (Sawada et al. 2007, Karashima et al. 2009, Chen et al. 2013). However, Trpal-deficient mice were indistinguishable from wild-type littermates when examined for behavioral responses to cold temperatures (Bautista et al. 2007, Knowlton et al. 2010), probably because of the presence of other cold-activated channels. In line with these findings, an additional lack of TRPA1 decreases cold avoidance in $\operatorname{Trpm} 8^{-/-}$mice in a temperature gradient assay (Winter et al. 2017). Surprisingly, rodent TRPA1 has been also found to mediate a crucial physiological role in the detection of noxious heat (Hoffmann et al. 2013, Vandewauw et al. 2018), similarly to other animal TRPA1 orthologues.
The thermal activation of human TRPA1 was for a long time a matter of debate. Human TRPA1 (hTRPA1) was found to be activated by $12{ }^{\circ} \mathrm{C}$ cooling, although to a lesser extent than mouse TRPA1 (mTRPA1) (Kremeyer et al. 2010, Wang et al. 2013, Moparthi et al. 2014, Moparthi et al. 2016, Sinica et al. 2019). However, other groups did not observe any hTRPA1 cold-evoked currents upon cooling (Jordt et al. 2004, Cordero-Morales et al. 2011, Chen et al. 2013). The single residue G878 in mTRPA1 (V875 in hTRPA1) accounts for differences in the cold sensitivity of hTRPA1 and mTRPA1 (Chen et al. 2013), and for the temperature-dependent kinetics of voltage activation (Sinica et al. 2019). The introduction of part of the rattlesnake TRPA1 or dTRPA1 N-terminus to hTRPA1 was sufficient to confer heat sensitivity to the human TRPA1, emphasizing the role of the N-terminus in heat activation (Cordero-Morales et al. 2011). However, human and mouse TRPA1 exhibited activation upon noxious heat stimulation above $50{ }^{\circ} \mathrm{C}$ (Hynkova et al. 2016, Sinica et al. 2019), potentially explaining why other authors have not seen such a high noxious heat threshold. Furthermore, the depolarizing voltage synergically increased the responses to heat (Sinica et al. 2019).

\section{Modulation of temperature activation by TRPA1 agonists}

Interestingly, the noxious-heat avoidance behavior of Drosophila with impaired dTRPA1 can be rescued by the expression of human or heat-insensitive planarian TRPA1 (Arenas et al. 2017). The authors suggest that TRPA1 activation is mediated by $\mathrm{H}_{2} \mathrm{O}_{2}$ and ROS, early markers of tissue damage that are rapidly produced as a result of heat exposure. Although warm temperature suppresses the activation effects of agonists such as AITC or menthol on rat and human TRPA1 orthologues (Wang et al. 2012), responses to $\mathrm{H}_{2} \mathrm{O}_{2}$ are potentiated by heat in Chinese hamster ovary $(\mathrm{CHO})$ cells expressing mTRPA1 (Vandewauw et al. 2018). The presence of reducing agents in the bath solution inhibited both the cold and warm responses of hTRPA1 reconstituted in an artificial membrane (Moparthi et al. 2016), implying the importance of the TRPA1 redox state in heat activation. On the other hand, mild cooling markedly increases currents evoked by electrophiles and carvacrol in rat and human TRPA1, suggesting that TRPA1 is a key mediator of cold hypersensitivity (del Camino et al. 2010, Moparthi et al. 2016, Zimova et al. 2020). The TRPA1-positive neurons only respond 
to cold in the presence of some agonists, suggesting that TRPA1 is important in pathological conditions with an elevated level of proinflammatory activators, but likely plays a comparatively minor role in acute cold sensation (del Camino et al. 2010). TRPA1 has been also linked with mechanical and cold allodynia accompanying nerve injury (Chen et al. 2011), inflammation (Yamaki et al. 2020), or anti-cancer treatment with oxaliplatin (Nassini et al. 2011, Park et al. 2015). Acute hypersensitivity to cold temperatures induced by oxaliplatin is mediated by human TRPA1 sensitization to ROS via mechanisms that are, in a dose-dependent manner, governed by the inhibition of propyl hydroxylases (Miyake et al. 2016). Thus, the products of oxidative stress resulting from the presence of noxious heat and cold temperatures might be the driving force that sensitizes the TRPA1 channels to be activated by temperature.

In order to see how the presence of agonist modulates the temperature sensitivity of the human and mouse TRPA1 channel, we used repeated linear voltage pulses from $-80 \mathrm{mV}$ to $+80 \mathrm{mV}$ with the combination of temperature changes and application of the non-covalent agonist carvacrol at a concentration of $50 \mu \mathrm{M}$ (Fig. 2A). The cells were held at $25^{\circ} \mathrm{C}$ and then exposed to 20 -s episodes of cooling or warming by $10^{\circ} \mathrm{C}$, first in the extracellular solution (ECS) and then in the presence of carvacrol. From the average currents obtained at the end of the episode, we calculated the potentiation effect (Fig. 2B). While the mouse TRPA1 was clearly activated by cold even in the absence of carvacrol, cold activation in human TRPA1 was not clearly visible because of the low basal currents. This result suggests that mouse TRPA1 seems to be less susceptible to modulation by temperature when the voltage sensor is activated, compared with the human orthologue. Surprisingly, both hTRPA1 and mTRPA1 are potentiated by cold at negative potentials even in the presence of carvacrol, as opposed to what (Moparthi et al. 2016) observed. This indicates that both channels are intrinsically activated by heat and that carvacrol uncovers the cold activation by shifting the equilibrium towards the open state of the channel. In addition, while warming increases the currents in the ECS, warmer temperatures of $35^{\circ} \mathrm{C}$ somewhat suppress the effect of carvacrol at negative potentials, further supporting the activation of both orthologues by cold. However, stimulation by a rather short and fast voltage protocol may result in measuring the currents far from the equilibrium. A longer interval of voltage and temperature stimulation might be beneficial to elucidate the intrinsic properties of the TRPA1 channel.

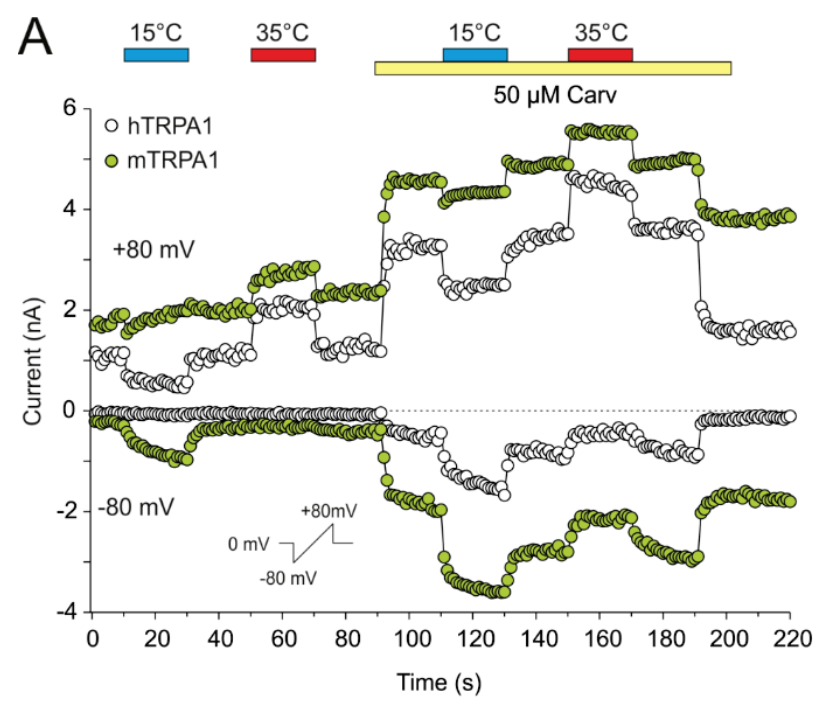

B
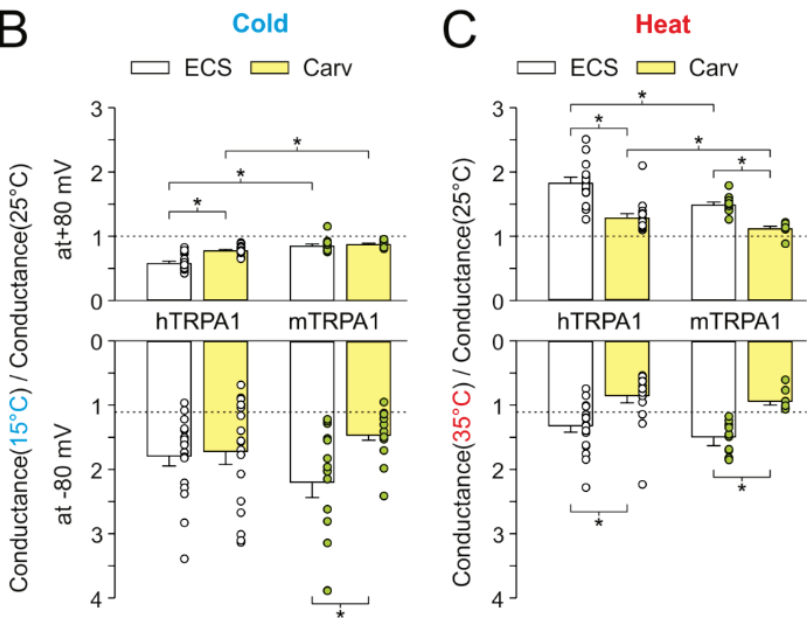

Fig. 2. Modulation of the voltage and temperature properties of the human and mouse TRPA1 channels by carvacrol. (A) Representative time courses of whole-cell currents from the human and mouse TRPA1 channels expressed in HEK293T cells, measured at $-80 \mathrm{mV}$ and $+80 \mathrm{mV}$, induced by repeated stimulation by a linear ramp protocol indicated in the inset. Cells were held at $25^{\circ} \mathrm{C}$ and were stimulated by 20 -s temperature changes to $15^{\circ} \mathrm{C}$ or $35^{\circ} \mathrm{C}$, first, in the extracellular solution (ECS), and then in the presence of noncovalent agonist carvacrol (Carv). Last five current responses of each cooling/heating episode and also the preceding episode at $25^{\circ} \mathrm{C}$ were averaged and transformed to conductances for further analysis. (B) Ratios of the conductances at the end of the cooling/heating episode, normalized by the conductances of the preceding currents at $25^{\circ} \mathrm{C}$, shown as vertical scatter plots and bar charts representing mean + S.E.M. $(n=9-18)$. Significant differences $(P<0.05)$ are highlighted with the asterisks.

\section{Bimodality of temperature activation and the induction of cold activation}

All these findings lead to the assumption that human and mouse TRPA1 channels exhibit a bimodal activation by temperature, exhibiting condition-dependent properties of both cold and heat channels. Single-channel 
recordings of hTRPA1 activity in the artificial membrane and measurements of intrinsic tryptophan fluorescence consolidate hTRPA1 as an intrinsic bidirectional thermosensor activated by both cold and heat. The authors found that hTRPA1 activation exhibits no single channel activity at a temperature around $22{ }^{\circ} \mathrm{C}$ (Moparthi et al. 2016). In agreement with this, our study (Sinica et al. 2019) shows that both the heating to $35^{\circ} \mathrm{C}$ and cooling to $15^{\circ} \mathrm{C}$ of human and mouse TRPA1 channels expressed in HEK293T cells increases the membrane currents, compared to $25^{\circ} \mathrm{C}$. The fact that mouse TRPA1 is markedly activated by cold probably reflects its shifted gating equilibrium towards the open state and not a steep temperature dependence of its kinetics of deactivation. Figure $3 \mathrm{~A}$ and $\mathrm{B}$ shows that both TRPA1 orthologues exhibited "U-shaped" outward currents at depolarizing voltage with a saddle point around room temperature. An increase in the currents produced by cold can be observed in both TRPA1 orthologues, while the increment of the currents above $25^{\circ} \mathrm{C}$ may also reflect the temperature dependence of the channel's unitary conductance
(Chen et al. 2013, Moparthi et al. 2016). Nevertheless, at even higher temperatures $\left(>45^{\circ} \mathrm{C}\right)$, TRPAl could exhibit the properties of a heat activated channel. The bidirectional effect of temperature can be even better seen when the channel is stimulated by temperature together with changes in the membrane voltage (Fig. 3C, D). Upon the exposure to noxious heat $\left(\sim 60^{\circ} \mathrm{C}\right)$, specific heat-induced currents can be observed with a steep temperature dependence over the temperature above $55^{\circ} \mathrm{C}$, providing the evidence to the bimodal activation of TRPA1 channels by noxious temperature. When the noxious temperature was above $60{ }^{\circ} \mathrm{C}$, the responses to depolarizing voltage of $+80 \mathrm{mV}$ were strongly reduced; the reduction correlated with the maximum temperature applied, suggesting that excessive heat irreversibly impedes either the activation of the voltage-sensor or its effective coupling to the gate. Our finding is in line with (Sanchez-Moreno et al. 2018), where the authors also observed the irreversible action of noxious heat above $50{ }^{\circ} \mathrm{C}$ at the TRPV1 channel, suppressing its subsequent activation by heat or agonist.

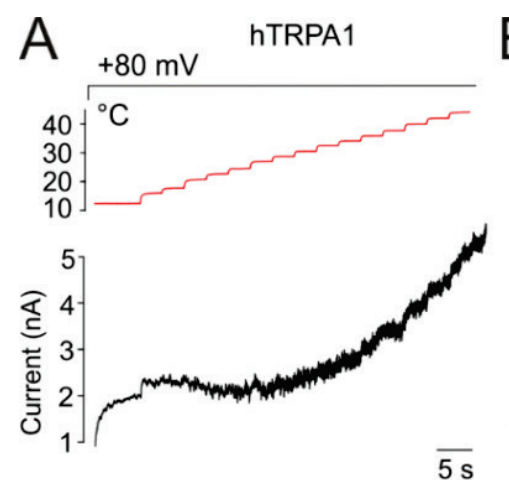

B
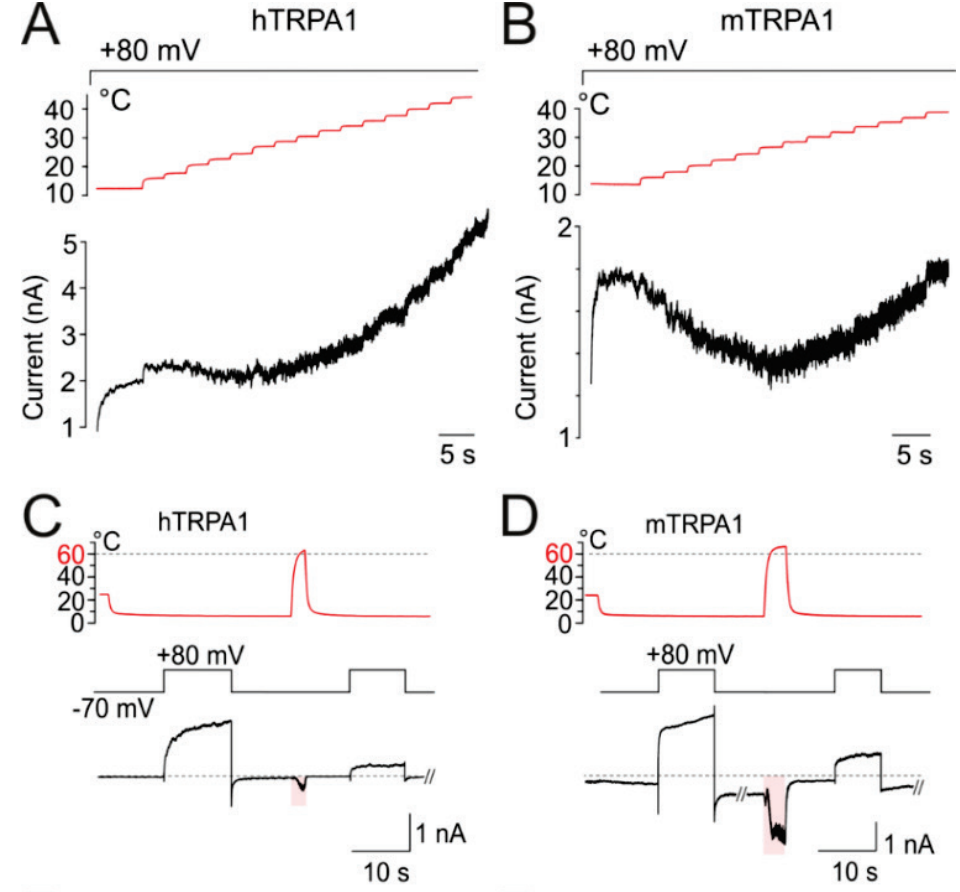

E
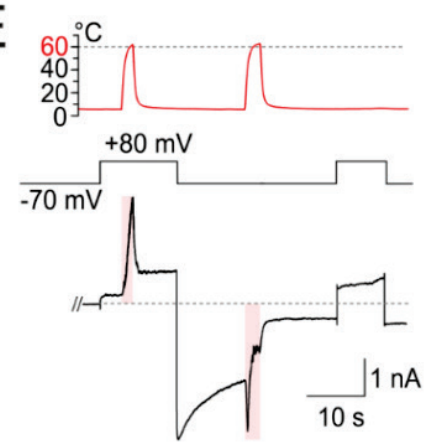

D

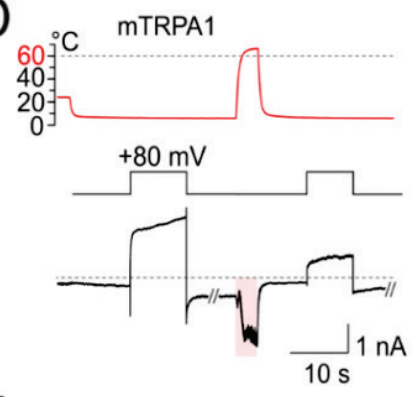

$\mathrm{F}$

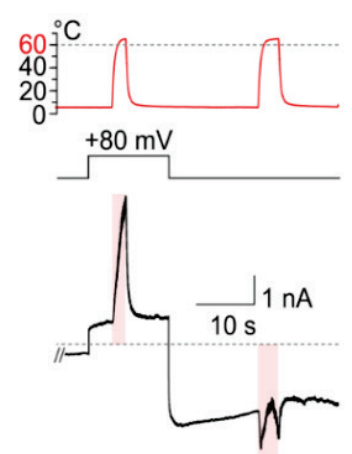

Fig. 3. Activation and modulation of TRPA1 by excessive heat. (A-B) Representative whole-cell currents of hTRPA1 and mTRPA1 channels transiently expressed in HEK293T cells, elicited by temperature steps ranging from $\sim 11$ to $\sim 52{ }^{\circ} \mathrm{C}$. The cells were held at constant depolarizing voltage $+80 \mathrm{mV}$. Note the "U-shaped" of the evoked currents. (C-D) Representative whole-cell currents of hTRPA1 and mTRPA1 channels. The cells were held at $-70 \mathrm{mV}$ and $\sim 8-10^{\circ} \mathrm{C}$, during the experiment, depolarizing pulses (+80 mV; gray area) and temperature above $60^{\circ} \mathrm{C}$ (pink area) was applied. In both orthologues, stimulation by excessive heat suppressed the concurrent activation by depolarization voltage. (E-F) The second part of the experiment from C-D. Concurrent stimulation of hTRPA1 and mTRPA1 by $+80 \mathrm{mV}$ and $>60^{\circ} \mathrm{C}$ turned the channel into the cold-activated mode upon following relaxation at $-70 \mathrm{mV}$. Additional heat stimulation released the channels back to their initial state. Adapted from (Sinica et al. 2019). 
Most interestingly, when the channels were, after concurrent stimulation by heat and depolarizing voltage first cooled down to $5{ }^{\circ} \mathrm{C}$ and then repolarized back to $-70 \mathrm{mV}$, highly pronounced inward currents were induced (Fig. 3E, F). The effect of cold-sensitized inward currents was not dependent on the order of the applied stimuli, but it was not seen when the reverse repolarization occurred in the presence of noxious heat. This 'heat-induced cold activation' was present in both mouse and human TRPA1, and in both the environment of HEK293T cells and in the neuronal F11 cell line. These striking findings indicate that noxious heat above $60{ }^{\circ} \mathrm{C}$ together with depolarizing voltage induces substantial structural rearrangements within the channel, leading to strong inward rectification at cold temperatures. The channel becomes inward-rectifying, being opened by negative membrane potential. Interestingly, in experiments described by (Moparthi et al. 2016), the cold potentiation of carvacrol-induced currents in hTRPA1 was only observed when channels were pre-exposed to warm temperatures. Thus, various sources of energy, such as those derived from agonist binding, or depolarization could drive the channel opening by cooling.

\section{The allosteric model and the existence of temperature sensors of the TRPA1 channel}

An allosteric model is capable of explaining the sensitization of an agonist-induced activation by temperature (del Camino et al. 2010), or, on the other hand, a loss of sensitivity to other stimuli at high concentrations of agonist (Matta and Ahern 2007). An allosteric model implies that the channel has a gate, described by an equilibrium constant $L$, and also independent voltage and thermal sensors, both described by their own constants $J$ and $K$ of the temperature- and voltage-dependent transitions. The sensors allosterically couple to the channel's gate and to each other according to the coupling energy terms $C, D$ and $E$, respectively (Salazar et al. 2011). Furthermore, the introduction of temperature-dependent coupling even gives rise to channels that respond to both cooling and heating (JaraOseguera and Islas 2013). An eight-state allosteric model with temperature-dependent coupling of the cold sensor to the gate was successfully used to model the bimodal properties of the TRPA1 channel in Fig. 3C-F (Sinica et al. 2019). The concurrent activation of the voltage and heat sensors can induce a conformational switch that leads to an increase in their energetic crosstalk $E$, an increase in the gating equilibrium constant $L$, and a drastic $(\sim 30,000$-fold) decrease in the coupling of the voltage sensor to the channel gate $D$. The channel also becomes inward-rectifying, being opened by hyperpolarized voltage.

How could these changes in allosteric properties be implemented into the structural context? The gate of the channel consists of two restrictions: the upper gate involves diagonal interactions between opposite D915 residues at the selective filter, and the lower gate of two hydrophobic seals formed by residues 1957 and V961 at the S6 helix (Paulsen et al. 2015). The residue L906 is extremely sensitive to substitutions, producing a strongly inward-rectifying phenotype with reduced sensitivity to TRPA1 inhibitor HC-030031 (Wan et al. 2014). Moreover, the introduction of a mosquito-to-human point mutation in the S6 helix and pore helix of dTRPA1 reverses the heat sensitivity to activation by cold (Wang et al. 2013). Thus, the concurrent application of excessive heat and voltage could potentially modulate the TRPA1 properties through the rearrangement of the pore helix.

\section{The candidates for temperature sensors}

The allosteric model suggests that the channel possesses independently operating voltage and temperature sensors. The existence of such sensors in the TRPA1 channel is still a matter of debate. In terms of a voltage sensor, TRP channels are only mildly activated by depolarizing voltage due to a low gating charge, as opposed to $\mathrm{K}^{+}$channels, where a voltage sensor contains several positive arginine residues (Jiang et al. 2003). However, the small gating charge of TRP channels is a crucial factor for the large voltage shifts induced by various stimuli (Nilius et al. 2005), and also an amplifier of thermal sensitivity (Chowdhury et al. 2014). A welldefined region of the TRPA1 channel involved in activation by heat is the tandemic assembly of 16 ankyrin repeat domains (ARD), structurally divided into the proximal part of AR12-AR16 stabilized by contacts with the coiled-coil domain of the C-terminus, and the unresolved distal part of AR1-AR11 that forms a crescent-like structure heading upward towards the plasma membrane (Paulsen et al. 2015) (Fig. 1B). Chimeric channel studies conducted on human, rattlesnake and Drosophila TRPA1 orthologues (hTRPA1, rsTRPA1 and dTRPA1) demonstrated that both parts of the ARD include two spatially distinct 
thermosensory modules - the primary module (AR10 AR15) and the enhancer module (AR3 - AR8) (CorderoMorales et al. 2011). Each module exhibits different average temperature coefficients of activation; thus together they modulate the overall thermal response properties of the native rsTRPA1 channel. The transfer of any of the rsTRPA1 modules or the primary module of dTRPA1 into the human TRPA1 orthologue is sufficient to introduce activation by temperature at $42{ }^{\circ} \mathrm{C}$ (CorderoMorales et al. 2011). The comparison of the primary sequences of TRPA1 orthologues of snakes with and without thermosensory properties led to the identification of 11 amino acid sites localized in the N-terminus that may be involved in the evolutionary adaptation of TRPA1 (Geng et al. 2011). In accordance with this finding, three single-point mutations at the AR6 of mTRPA1 are individually sufficient to make the channel activated by $40^{\circ} \mathrm{C}$, while leaving the sensitivity to chemicals unaffected (Jabba et al. 2014). Thus, the perturbations inside the ARDs may shift the threshold of the temperature sensor. However, the mosquito (AgTRPA1) orthologue reconstituted in artificial membrane retains its thermosensitivity toward $35^{\circ} \mathrm{C}$ even if its $\mathrm{N}$-terminus is deleted, suggesting that the $\mathrm{N}$-terminal domain may tune the response but is not required for the activation by these stimuli (Survery et al. 2016).

In TRP channels, the thermal opening of the channel involves a large change in conformational standard-state enthalpy. The authors (Clapham and Miller 2011) proposed that the gating of the TRP channels may be connected with folding/unfolding or wetting/dewetting processes associated with the changes in molar heat capacity. As a result, the channel can have a temperature sensor delocalized into many regions across the whole channel. Point mutations in specific regions of the channel may then influence the temperature activation by shifting the melting temperature $T_{m}$ along the temperature axis. In addition, unfolding processes can be induced by both hot and cold temperature. Therefore, the heat and cold activation can involve the same mechanism in cases where both the heat and cold denaturation temperatures are experimentally (or physiologically) accessible. To date, however, researchers have only experimentally observed heat denaturation in connection with the gating of TRP channels (Diaz-Franulic et al. 2020).

The folding/unfolding processes have to take part in regions that are allosterically coupled to the channel's gate. A shining example of such coupling is the
C-terminal coiled-coil of the bacterial voltage-gated sodium channel $\left(\mathrm{BacNa}_{\mathrm{v}}\right)$ and TRPM8 channel: while the $\mathrm{BacNa}_{\mathrm{v}}$ channel is heat-activated by partial coiled-coil unfolding (Arrigoni et al. 2016); in TRPM8, the activation occurs after coiled-coil stabilization upon cooling down to $15{ }^{\circ} \mathrm{C}$ (Diaz-Franulic et al. 2020). The coiled-coil domain of the TRPA1 channel is distinct from canonical coiled-coils due to two polar residues inside the structure and a rather hydrophobic exposed surface that interacts with ARD (Paulsen et al. 2015). A partial unfolding of coiled-coil helices occurs upon increasing the temperature to $42{ }^{\circ} \mathrm{C}$, although the multimerization remained unaffected (Martinez and Gordon 2019). Under the condition of positive coupling into the gate, the unfolding process of the coiled-coil domain might explain the remainder of the thermosensitivity in the absence of the N-terminus (Survery et al. 2016).

\section{The transmembrane domain and the crucial role of annular lipids}

The structural changes at the periphery have to be transduced into the TMD to further allosterically influence the structural segments that are functionally related to the upper and lower gates of the channel. According to the recently published structure of the open state of the TRPA1 channel in the presence of an electrophilic agonist, the transition from the closed to the open state involves the rotation of the entire TMD and also the S1-S4 domain, upwards translation of the pore helices and the straightening of the S4-S5 linker and the S5 segment into a single helix (Zhao et al. 2020). The allosteric coupling between the VSLD and PD is further supported by the evolutionary analysis of the primary sequences of TRPV1 and TRPM8 (Hilton et al. 2019). The sequential connection between the VSLD and PD is established by the S4-S5 linker. Increased attention is paid to the role of membrane lipids in the activation mechanisms of TRP channels by ligands and temperature (Fig. 4A). In the structurally related TRPV1, the displacement of a phosphatidylinositol molecule from the position between the VSLD, the S4-S5 linker, and the S5 helix was proposed as a mechanism of activation by heat and vanilloids (Gao et al. 2016). A molecule of phosphatidylcholine resides at an analogous position in the cryo-EM structure of the TRPA1 channel, establishing salt bridges with E864 and K868 from the S4-S5 linker and D802 from the S3 helix (Fig. 4B) (Suo et al. 2020). Displacement of this lipid with the specific 
non-covalent agonist GNE511 or by the introduction of bulky tryptophan mutation E864W into its binding site renders the channel open, suggesting its involvement in the mechanisms of gating (Liu et al. 2020). The activation by GNE511 is insensitive to TRPA1 antagonists and does not show signs of desensitization. The charge-swap mutation K868E produced a constitutively open channel with impaired voltage and electrophilic activation, as well as $\mathrm{Ca}^{2+}$-dependent potentiation and inactivation (Zima et al. 2015), potentially indicating the destabilization of the lipid from its binding site. On the other hand, the neutralization of D802 slowed the activation and deactivation kinetics and specifically affected the activation by electrophiles
(Zimova et al. 2018). Intriguingly, a human-to-mouse substitution of the nearby serine S804N as well as S804D mutation also severely suppressed the kinetics and created a cold-activated channel, while a neutralizing mutation S804A in the S3 helix produced a nonfunctional channel (Sinica et al. 2019). The residue S804 is around $5 \AA$ away from the intersubunit lipid, and it may also face inside the VSLD cavity. The mutation S804N may affect the gating-related movements of the channel or the binding of the lipids, potentially revealing the structural background of the main difference between the gating equilibrium of human and mouse TRPA1 orthologues.

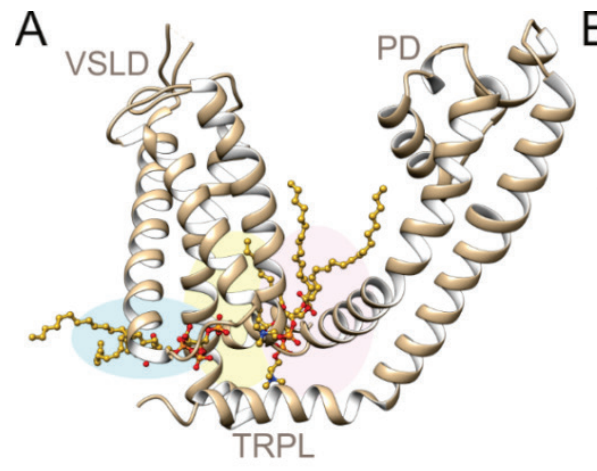

C
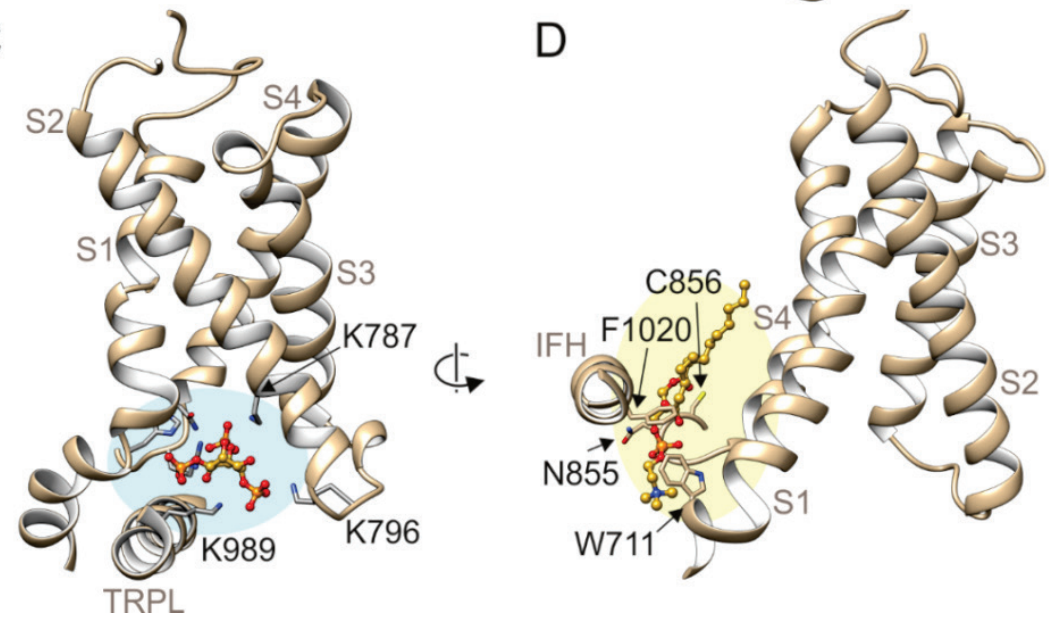

Fig. 4. Lipid-binding sites in TRPA1. (A) Three functionally important lipidbinding sites are shown in the structure of the transmembrane region of unliganded human TRPA1 subunit (Protein Databank, PDB, ID: 6PQQ). VSLD, voltage sensor-like domain; $P D$, pore domain; TRPL, TRP-like domain. (B-D) A close-up view of the lipids shaded by colors in $A$. The main interacting amino acids are depicted using their one-letter codes.

\section{Intracellular cavities as an integrative allosteric sites of TRPA1 modulation}

The S804 residue is inside an intracellular, solvent-accessible cavity formed by four helical segments S1-S4 of VSLD and the TRPL helix. The VSLD intracellular cavity is a conserved regulatory element across TRP channels. Our results from (Zimova et al. 2018) show the importance of polar and charged residues inside the cavity as crucial determinants of the electrophilic, voltage and calcium sensitivity of TRPA1 (Fig. 4C). The results from molecular docking experiments suggest that the intracellular cavity might be a binding site of terpene agonists including carvacrol, thymol and $\beta$-myrcene, which is in agreement with the presence of icilin and menthol inside the cavity in the related TRPM8 channel (Yin et al. 2019). In addition, the docking simulations indicate the possibility of a lipid binding inside the VSLD cavity, specifically the negatively charged head group of phosphatidylinositol 
4,5-bisphosphate $\left(\mathrm{PIP}_{2}\right)$ (Zimova et al. 2018) and cholesterol (Startek et al. 2019a). The possibility of a lipid binding into the intracellular cavity further narrows the localization of phosphatidylcholine in the cryo-EM structure of the TRPV1 channel (Gao et al. 2016). Neutralization of the positively charged residues contacting the inositol head group of $\mathrm{PIP}_{2}$ impaired the voltage- and agonist-driven activation of the TRPA1 channel, while the neutralization of negatively charged E788 and E808 resulted in gain-of-function mutations (Zimova et al. 2018). These modulation effects may be attributed to changes in the electrostatic potential inside the cavity and altered binding of $\mathrm{PIP}_{2}$. Depletion of the membrane $\mathrm{PIP}_{2}$ downregulates the wild-type TRPA1 channels and transformed the gain-of-function mutant E808A back to the wild-type level (Zimova et al. 2018). Importantly, the effects of $\mathrm{PIP}_{2}$ deletions were absent in the presence of extracellular calcium, which is in line with the finding that four negatively charged residues (including E788 and E808 in hTRPA1) directly bind $\mathrm{Ca}^{2+}$ ions and mediate the $\mathrm{Ca}^{2+}$-dependent modulation of TRPA1 (Zimova et al. 2018, Zhao et al. 2020) and other members of TRPC (Duan et al. 2018, Duan et al. 2019) and TRPM channels (Autzen et al. 2018, Zhang et al. 2018, Diver et al. 2019).

Another important allosteric site of the modulation of the TRPA1 channel is an interfacial cavity formed by S4, the S4-S5 linker, pre-S1, S1, and the C-terminal interfacial helix (Fig. 4D). The results from the web server-based method for predicting the interaction between peptides and anionic lipids (Lata et al. 2007) suggested that the IFH is capable of binding lipids that may potentially regulate the channel's activity (Witschas et al. 2015). With the use of biophysical methods, our team has proved that the peptide T1003P1034 covering the IFH only interacts with the lipid membrane in the presence of $\mathrm{PIP}_{2}$ (Macikova et al. 2019). A molecule of an annular lipid was localized in the cryo-EM structure of the TRPA1-C621S channel with a benzyl isothiocyanate (BITC) molecule bound to its binding site in the coupling domain. The lipid is not present in cryo-EM structures of TRPA1-C621S without an agonist (PDB ID: 6PQQ) and with the larger agonist JT010 (PDB ID: 6PQO), because of the closer position of the IFH toward the VSLD and consequently reduced cavity size (Suo et al. 2020). In support of this finding, the substitution of the conserved phenylalanine F1020 in the IFH helix with glycine suppressed the currents evoked by the electrophilic agonist cinnamaldehyde
(Cin), but only at negative potentials. The $\mathrm{Ca}^{2+}$-dependent potentiation and inactivation were unaffected (Macikova et al. 2019). Furthermore, it has been shown that from nanomolar concentrations of intracellular $\mathrm{Ca}^{2+}$, the region next to the IFH acts as a binding site for the $\mathrm{Ca}^{2+} /$ calmodulin complex that potentiates the TRPA1 channel under resting conditions (Hasan et al. 2017). The inclusion of the T1003-P1034 peptide in the intracellular solution prevented $\mathrm{Ca}^{2+}$-dependent potentiation, similarly as in (Hasan et al. 2017), suggesting that the $\mathrm{Ca}^{2+} /$ calmodulin complex may compete for the same or overlapping binding site with $\mathrm{PIP}_{2}$ (Macikova et al. 2019).

The other part of the cavity recognized as the region determining the sensitivity to several activation stimuli is composed of the S5 helix and the S4-S5 linker of the neighboring subunit. At the S4-S5 linker there is a cysteine residue $\mathrm{C} 856$ that was recognized with the use of calcium imaging as being one of the main targets of $\mathrm{O}_{2}$ in hyperoxia, because the C856S mutant exhibited suppressed hyperoxia-induced currents at basal potential (Takahashi et al. 2011). We wanted to also see the involvement of this residue in the activation by electrophiles. Figure 5 shows the currents measured from HEK293T cells expressing the wild-type of hTRPA1 or the C856S or the C856A mutant by the repeated protocol as in (Macikova et al. 2019). Surprisingly, both mutant channels were already strongly suppressed at negative membrane potentials before the application of electrophiles (Fig. 5A). The impairment of the channel's function at these negative potentials continued in the presence of $\mathrm{Cin}$ and the subsequent application of $\mathrm{Ca}^{2+}$ ions (Fig. 5B). The stronger agonist AITC was able to activate both mutants to the level of the wild type, although the impairment at negative potentials was still visible (Fig. 5C). These findings imply that the C856S mutation probably impaired the coupling of the voltage sensor into the gate more pronouncedly than in the F1020G mutant (Macikova et al. 2019), suggesting the involvement of the interfacial cavity in the allosteric coupling of the voltage sensor and the gating of the channel.

In the S4-S5 linker, next to the C856S, there is the human channelopathy-related residue N855, the mutation of which induced an $\sim 5$-fold increase in inward currents upon activation by cold compared with wild-type hTRPA1 (Kremeyer et al. 2010). Also, the mouse-tohuman mutation G878V in S5 accounts for the differences in the cold sensitivity of hTRPA1 and 
mTRPA1 by changing the temperature dependence of their deactivation kinetics (Chen et al. 2013, Sinica et al. 2019). The same region also acts as a binding site for menthol (Xiao et al. 2008), which potentially explains the synergic effects of menthol and structurally related carvacrol on cold activation. In addition, the human-tomouse mutation H1018R in the IFH exhibited significantly increased carvacrol responses upon cooling to $15^{\circ} \mathrm{C}$ (Zimova et al. 2020). On the other hand, the coexpression of the human TRPA1 channel with the voltage-sensitive phosphatase from Danio Rerio (Dr-VSP), which depletes the acute levels of $\mathrm{PIP}_{2}$, reduced the cold responses to $15^{\circ} \mathrm{C}$ while leaving the carvacrol-cold synergy unaffected (Zimova et al. 2020).
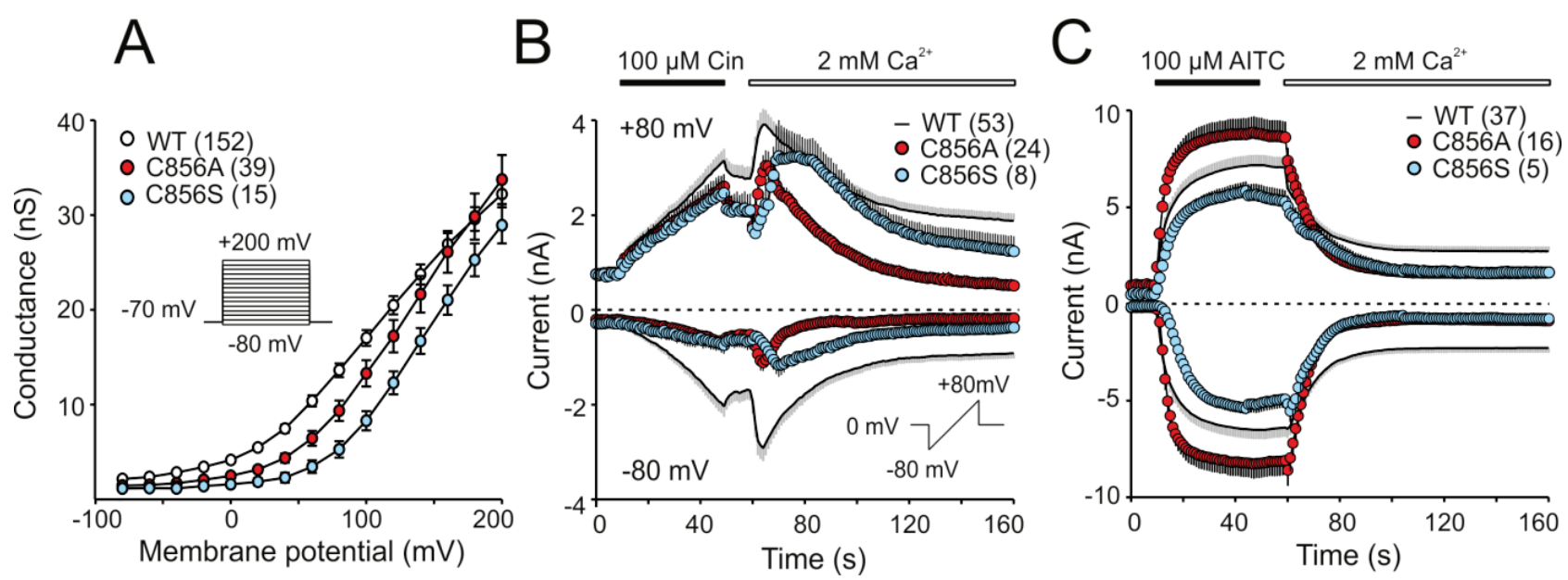

Fig. 5. Mutations of C856 in the S4-S5 linker impair the channel opening at resting potentials. (A) Average conductance-voltage relationships of humanTRPA1 wild-type (WT) and indicated mutations expressed in HEK293T cells, measured at the end of the included voltage-step protocol from (Zimova et al. 2018). (B-C) Time course of the average currents of the TRPA1 wild-type (black line) and indicated mutants, measured by the indicated ramp protocol applied every second, at $-80 \mathrm{mV}$ and $+80 \mathrm{mV}$. The cells were first exposed to electrophilic agonists, cinnamaldehyde (Cin) or allyl isothiocyanate (AITC), and then to $2 \mathrm{mM}$ of $\mathrm{Ca}^{2+}$ ions. Note the suppressed current of indicated mutants at negative potentials. Data are shown as mean \pm (or $+/-$ ) S.E.M., $\mathrm{n}$ is indicated in brackets. Bath solution and pipette solution was used as described in (Zimova et al. 2018).

\section{Concluding remarks}

In this review, we have covered and counted various approaches to regulating the thermosensitivity of TRPA1 channels. The TRPA1 channels are evolutionarily designed to be polymodal channels with the ability to effect the interaction of several modulation stimuli. Their functional adaptations to the environmental stimuli, specific expression patterns, splicing variants, evolutionary pressure, cooperation with other proteins (TRPV1 channel, $\mathrm{Ca}^{2+} /$ calmodulin complex and others) substantially aid the profiling of the channels to suit their roles as polymodal sensors. The growing number of structural and functional findings in the field related to TRP channels allows us to integrate the known knowledge and make progress on the molecular mechanisms of the polymodal regulation, mechanisms of bimodal temperature activation and the channel gating. Furthermore, the recent structural findings of the role of membrane lipids may help to find a specific mode of action of the TRPA1 channel, which could be used to specifically target the allosteric effects of temperature, providing aid for pain-related TRPA1-mediated pathophysiological conditions.

\section{Conflict of Interest}

There is no conflict of interest.

\section{Acknowledgements}

This work was supported by the Czech Science Foundation (19-03777S).

\section{References}

AKASHI HD, SAITO S, CADIZ DIAZ A, MAKINO T, TOMINAGA M, KAWATA M: Comparisons of behavioural and TRPA1 heat sensitivities in three sympatric Cuban Anolis lizards. Mol Ecol 27: 2234-2242, 2018. https://doi.org/10.1111/mec.14572 
ARENAS OM, ZAHARIEVA EE, PARA A, VASQUEZ-DOORMAN C, PETERSEN CP, GALLIO M: Activation of planarian TRPA1 by reactive oxygen species reveals a conserved mechanism for animal nociception. Nat Neurosci 20: 1686-1693, 2017. https://doi.org/10.1038/s41593-017-0005-0

ARRIGONI C, ROHAIM A, SHAYA D, FINDEISEN F, STEIN RA, NURVA SR, MISHRA S, MCHAOURAB HS, MINOR DL JR: Unfolding of a temperature-sensitive domain controls voltage-gated channel activation. Cell 164: 922-936, 2016. https://doi.org/10.1016/j.cell.2016.02.001

AUTZEN HE, MYASNIKOV AG, CAMPBELL MG, ASARNOW D, JULIUS D, CHENG Y: Structure of the human TRPM4 ion channel in a lipid nanodisc. Science 359: 228-232, 2018. https://doi.org/10.1126/science.aar4510

BANDELL M, STORY GM, HWANG SW, VISWANATH V, EID SR, PETRUS MJ, EARLEY TJ, PATAPOUTIAN A: Noxious cold ion channel TRPA1 is activated by pungent compounds and bradykinin. Neuron 41: 849-857, 2004. https://doi.org/10.1016/S0896-6273(04)00150-3

BAUTISTA DM, JORDT SE, NIKAI T, TSURUDA PR, READ AJ, POBLETE J, YAMOAH EN, BASBAUM AI, JULIUS D: TRPA1 mediates the inflammatory actions of environmental irritants and proalgesic agents. Cell 124: 1269-1282, 2006. https://doi.org/10.1016/j.cell.2006.02.023

BAUTISTA DM, SIEMENS J, GLAZER JM, TSURUDA PR, BASBAUM AI, STUCKY CL, JORDT SE, JULIUS D: The menthol receptor TRPM8 is the principal detector of environmental cold. Nature 448: 204-208, 2007. https://doi.org/10.1038/nature05910

BIANCHI BR, ZHANG XF, REILLY RM, KYM PR, YAO BB, CHEN J: Species comparison and pharmacological characterization of human, monkey, rat, and mouse TRPA1 channels. J Pharmacol Exp Ther 341: 360-368, 2012. https://doi.org/10.1124/jpet.111.189902

CHEN J, JOSHI SK, DIDOMENICO S, PERNER RJ, MIKUSA JP, GAUVIN DM, SEGRETI JA, HAN P, ZHANG XF, NIFORATOS W, BIANCHI BR, BAKER SJ, ZHONG C, SIMLER GH, MCDONALD HA, SCHMIDT RG, MCGARAUGHTY SP, CHU KL, FALTYNEK CR, KORT ME, REILLY RM, KYM PR: Selective blockade of TRPA1 channel attenuates pathological pain without altering noxious cold sensation or body temperature regulation. Pain 152: 1165-1172, 2011. https://doi.org/10.1016/j.pain.2011.01.049

CHEN J, KANG D, XU J, LAKE M, HOGAN JO, SUN C, WALTER K, YAO B, KIM D: Species differences and molecular determinant of TRPA1 cold sensitivity. Nat Commun 4: 2501, 2013. https://doi.org/10.1038/ncomms3501

CHEN J, KYM PR: TRPA1: the species difference. J Gen Physiol 133: 623-625, 2009. https://doi.org/10.1085/jgp.200910246

CHOWDHURY S, JARECKI BW, CHANDA B: A molecular framework for temperature-dependent gating of ion channels. Cell 158: 1148-1158, 2014. https://doi.org/10.1016/j.cell.2014.07.026

CLAPHAM DE, MILLER C: A thermodynamic framework for understanding temperature sensing by transient receptor potential (TRP) channels. Proc Natl Acad Sci U S A 108: 19492-19497, 2011. https://doi.org/10.1073/pnas.1117485108

CORDERO-MORALES JF, GRACHEVA EO, JULIUS D: Cytoplasmic ankyrin repeats of transient receptor potential A1 (TRPA1) dictate sensitivity to thermal and chemical stimuli. Proc Natl Acad Sci U S A 108: E1184-E1191, 2011. https://doi.org/10.1073/pnas.1114124108

DAI Y: TRPs and pain. Semin Immunopathol 38: 277-291, 2016. https://doi.org/10.1007/s00281-015-0526-0

DEL CAMINO D, MURPHY S, HEIRY M, BARRETT LB, EARLEY TJ, COOK CA, PETRUS MJ, ZHAO M, D'AMOURS M, DEERING N, BRENNER GJ, COSTIGAN M, HAYWARD NJ, CHONG JA, FANGER CM, WOOLF CJ, PATAPOUTIAN A, MORAN MM: TRPA1 contributes to cold hypersensitivity. J Neurosci 30: 15165-15174, 2010. https://doi.org/10.1523/JNEUROSCI.2580-10.2010

DIAZ-FRANULIC I, RADDATZ N, CASTILLO K, GONZALEZ-NILO FD, LATORRE R: A folding reaction at the C-terminal domain drives temperature sensing in TRPM8 channels. Proc Natl Acad Sci U S A 117: 20298-20304, 2020. https://doi.org/10.1073/pnas.2004303117

DIVER MM, CHENG Y, JULIUS D: Structural insights into TRPM8 inhibition and desensitization. Science 365: 1434-1440, 2019. https://doi.org/10.1126/science.aax6672

DU EJ, KANG K: A single natural variation determines cytosolic $\mathrm{Ca}(2+)$-mediated hyperthermosensitivity of TRPA1s from rattlesnakes and boas. Mol Cells 43: 572-580, 2020. 
DUAN J, LI J, CHEN GL, GE Y, LIU J, XIE K, PENG X, ZHOU W, ZHONG J, ZHANG Y, XU J, XUE C, LIANG B, ZHU L, LIU W, ZHANG C, TIAN XL, WANG J, CLAPHAM DE, ZENG B, LI Z, ZHANG J: Cryo-EM structure of TRPC5 at 2.8-A resolution reveals unique and conserved structural elements essential for channel function. Sci Adv 5: eaaw7935, 2019. https://doi.org/10.1126/sciadv.aaw7935

DUAN J, LI J, ZENG B, CHEN GL, PENG X, ZHANG Y, WANG J, CLAPHAM DE, LI Z, ZHANG J: Structure of the mouse TRPC4 ion channel. Nat Commun 9: 3102, 2018. https://doi.org/10.1038/s41467-018-05247-9

EIGENBROD O, DEBUS KY, REZNICK J, BENNETT NC, SANCHEZ-CARRANZA O, OMERBASIC D, HART DW, BARKER AJ, ZHONG W, LUTERMANN H, KATANDUKILA JV, MGODE G, PARK TJ, LEWIN GR: Rapid molecular evolution of pain insensitivity in multiple African rodents. Science 364: 852-859, 2019. https://doi.org/10.1126/science.aau0236

GAO Y, CAO E, JULIUS D, CHENG Y: TRPV1 structures in nanodiscs reveal mechanisms of ligand and lipid action. Nature 534: 347-351, 2016. https://doi.org/10.1038/nature17964

GAU P, POON J, UFRET-VINCENTY C, SNELSON CD, GORDON SE, RAIBLE DW, DHAKA A: The zebrafish ortholog of TRPV1 is required for heat-induced locomotion. J Neurosci 33: 5249-5260, 2013. https://doi.org/10.1523/JNEUROSCI.5403-12.2013

GENG J, LIANG D, JIANG K, ZHANG P: Molecular evolution of the infrared sensory gene TRPA1 in snakes and implications for functional studies. PLoS One 6: e28644, 2011. https://doi.org/10.1371/journal.pone.0028644

GHOSH M, SCHEPETKIN IA, OZEK G, OZEK T, KHLEBNIKOV AI, DAMRON DS, QUINN MT: Essential Oils from Monarda fistulosa: Chemical composition and activation of transient receptor potential A1 (TRPA1) Channels. Molecules 25: 4873, 2020. https://doi.org/10.3390/molecules25214873

GRACHEVA EO, CORDERO-MORALES JF, GONZALEZ-CARCACIA JA, INGOLIA NT, MANNO C, ARANGUREN CI, WEISSMAN JS, JULIUS D: Ganglion-specific splicing of TRPV1 underlies infrared sensation in vampire bats. Nature 476: 88-91, 2011. https://doi.org/10.1038/nature10245

GRACHEVA EO, INGOLIA NT, KELLY YM, CORDERO-MORALES JF, HOLLOPETER G, CHESLER AT, SANCHEZ EE, PEREZ JC, WEISSMAN JS, JULIUS D: Molecular basis of infrared detection by snakes. Nature 464: 1006-1011, 2010. https://doi.org/10.1038/nature08943

GU P, GONG J, SHANG Y, WANG F, RUPPELL KT, MA Z, SHEEHAN AE, FREEMAN MR, XIANG Y: Polymodal nociception in drosophila requires alternative splicing of TrpA1. Curr Biol 29: 3961-3973 e3966, 2019. https://doi.org/10.1016/j.cub.2019.09.070

GUPTA R, SAITO S, MORI Y, ITOH SG, OKUMURA H, TOMINAGA M: Structural basis of TRPA1 inhibition by HC-030031 utilizing species-specific differences. Sci Rep 6: 37460, 2016. https://doi.org/10.1038/srep37460

HAMADA FN, ROSENZWEIG M, KANG K, PULVER SR, GHEZZI A, JEGLA TJ, GARRITY PA: An internal thermal sensor controlling temperature preference in Drosophila. Nature 454: 217-220, 2008. https://doi.org/10.1038/nature07001

HASAN R, LEESON-PAYNE AT, JAGGAR JH, ZHANG X: Calmodulin is responsible for Ca2+-dependent regulation of TRPA1 Channels. Sci Rep 7: 45098, 2017. https://doi.org/10.1038/srep46588

HILTON JK, KIM M, VAN HORN WD: Structural and evolutionary insights point to allosteric regulation of TRP ion channels. Acc Chem Res 52: 1643-1652, 2019. https://doi.org/10.1021/acs.accounts.9b00075

HOFFMANN T, KISTNER K, MIERMEISTER F, WINKELMANN R, WITTMANN J, FISCHER MJ, WEIDNER C, REEH PW: TRPA1 and TRPV1 are differentially involved in heat nociception of mice. Eur J Pain 17: 1472-1482, 2013. https://doi.org/10.1002/j.1532-2149.2013.00331.x

HOFFSTAETTER LJ, BAGRIANTSEV SN, GRACHEVA EO: TRPs et al.: a molecular toolkit for thermosensory adaptations. Pflugers Arch 470: 745-759, 2018. https://doi.org/10.1007/s00424-018-2120-5

HUFFER KE, ALEKSANDROVA AA, JARA-OSEGUERA A, FORREST LR, SWARTZ KJ: Global alignment and assessment of TRP channel transmembrane domain structures to explore functional mechanisms. Elife 9: e58660, 2020. https://doi.org/10.7554/eLife.58660

HWANG RY, STEARNS NA, TRACEY WD: The ankyrin repeat domain of the TRPA protein painless is important for thermal nociception but not mechanical nociception. PLoS One 7: e30090, 2012. https://doi.org/10.1371/journal.pone.0030090 
HYNKOVA A, MARSAKOVA L, VASKOVA J, VLACHOVA V: N-terminal tetrapeptide T/SPLH motifs contribute to multimodal activation of human TRPA1 channel. Sci Rep 6: 28700, 2016. https://doi.org/10.1038/srep28700

JABBA S, GOYAL R, SOSA-PAGAN JO, MOLDENHAUER H, WU J, KALMETA B, BANDELL M, LATORRE R, PATAPOUTIAN A, GRANDL J: Directionality of temperature activation in mouse TRPA1 ion channel can be inverted by single-point mutations in ankyrin repeat six. Neuron 82: 1017-1031, 2014. https://doi.org/10.1016/j.neuron.2014.04.016

JARA-OSEGUERA A, ISLAS LD: The role of allosteric coupling on thermal activation of thermo-TRP channels. Biophys J 104: 2160-2169, 2013. https://doi.org/10.1016/j.bpj.2013.03.055

JIANG Y, RUTA V, CHEN J, LEE A, MACKINNON R: The principle of gating charge movement in a voltagedependent K+ channel. Nature 423: 42-48, 2003. https://doi.org/10.1038/nature01581

JORDT SE, BAUTISTA DM, CHUANG HH, MCKEMY DD, ZYGMUNT PM, HOGESTATT ED, MENG ID, JULIUS D: Mustard oils and cannabinoids excite sensory nerve fibres through the TRP channel ANKTM1. Nature 427: 260-265, 2004. https://doi.org/10.1038/nature02282

KANG K: Exceptionally high thermal sensitivity of rattlesnake TRPA1 correlates with peak current amplitude. Biochim Biophys Acta 1858: 318-325, 2016. https://doi.org/10.1016/j.bbamem.2015.12.011

KANG K, PANZANO VC, CHANG EC, NI L, DAINIS AM, JENKINS AM, REGNA K, MUSKAVITCH MA, GARRITY PA: Modulation of TRPA1 thermal sensitivity enables sensory discrimination in Drosophila. Nature 481: 76-80, 2011. https://doi.org/10.1038/nature10715

KANG K, PULVER SR, PANZANO VC, CHANG EC, GRIFFITH LC, THEOBALD DL, GARRITY PA: Analysis of Drosophila TRPA1 reveals an ancient origin for human chemical nociception. Nature 464: 597-600, 2010. https://doi.org/10.1038/nature08848

KARASHIMA Y, DAMANN N, PRENEN J, TALAVERA K, SEGAL A, VOETS T, NILIUS B: Bimodal action of menthol on the transient receptor potential channel TRPA1. J Neurosci 27: 9874-9884, 2007. https://doi.org/10.1523/JNEUROSCI.2221-07.2007

KARASHIMA Y, TALAVERA K, EVERAERTS W, JANSSENS A, KWAN KY, VENNEKENS R, NILIUS B, VOETS T: TRPA1 acts as a cold sensor in vitro and in vivo. Proc Natl Acad Sci U S A 106: 1273-1278, 2009. https://doi.org/10.1073/pnas.0808487106

KASTENHUBER E, GESEMANN M, MICKOLEIT M, NEUHAUSS SC: Phylogenetic analysis and expression of zebrafish transient receptor potential melastatin family genes. Dev Dyn 242: 1236-1249, 2013. https://doi.org/10.1002/dvdy.24020

KNOWLTON WM, BIFOLCK-FISHER A, BAUTISTA DM, MCKEMY DD: TRPM8, but not TRPA1, is required for neural and behavioral responses to acute noxious cold temperatures and cold-mimetics in vivo. Pain 150: 340-350, 2010. https://doi.org/10.1016/j.pain.2010.05.021

KOHNO K, SOKABE T, TOMINAGA M, KADOWAKI T: Honey bee thermal/chemical sensor, AmHsTRPA, reveals neofunctionalization and loss of transient receptor potential channel genes. J Neurosci 30: 12219-12229, 2010. https://doi.org/10.1523/JNEUROSCI.2001-10.2010

KREMEYER B, LOPERA F, COX JJ, MOMIN A, RUGIERO F, MARSH S, WOODS CG, JONES NG, PATERSON KJ, FRICKER FR, VILLEGAS A, ACOSTA N, PINEDA-TRUJILLO NG, RAMIREZ JD, ZEA J, BURLEY MW, BEDOYA G, BENNETT DL, WOOD JN, RUIZ-LINARES A: A gain-of-function mutation in TRPA1 causes familial episodic pain syndrome. Neuron 66: 671-680, 2010. https://doi.org/10.1016/j.neuron.2010.04.030

LATA S, SHARMA BK, RAGHAVA GP: Analysis and prediction of antibacterial peptides. BMC Bioinformatics 8: 263, 2007. https://doi.org/10.1186/1471-2105-8-263

LAURSEN WJ, BAGRIANTSEV SN, GRACHEVA EO: TRPA1 channels: chemical and temperature sensitivity. Curr Top Membr 74: 89-112, 2014. https://doi.org/10.1016/B978-0-12-800181-3.00004-X

LIU C, REESE R, VU S, ROUGE L, SHIELDS SD, KAKIUCHI-KIYOTA S, CHEN H, JOHNSON K, SHI YP, CHERNOV-ROGAN T, GREINER DMZ, KOHLI PB, HACKOS D, BRILLANTES B, TAM C, LI T, WANG J, SAFINA B, MAGNUSON S, VOLGRAF M, PAYANDEH J, ZHENG J, ROHOU A, CHEN J: A noncovalent ligand reveals biased agonism of the TRPA1 ion channel. Neuron 109: 273-284.e4, 2021. https://doi.org/10.1016/j.neuron.2020.10.014 
LUO J, SHEN WL, MONTELL C: TRPA1 mediates sensation of the rate of temperature change in Drosophila larvae. Nat Neurosci 20: 34-41, 2017. https://doi.org/10.1038/nn.4416

MACIKOVA L, SINICA V, KADKOVA A, VILLETTE S, CIACCAFAVA A, FAHERTY J, LECOMTE S, ALVES ID, VLACHOVA V: Putative interaction site for membrane phospholipids controls activation of TRPA1 channel at physiological membrane potentials. FEBS J 286: 3664-3683, 2019. https://doi.org/10.1111/febs.14931

MARONE IM, DE LOGU F, NASSINI R, DE CARVALHO GONCALVES M, BENEMEI S, FERREIRA J, JAIN P, LI PUMA S, BUNNETT NW, GEPPETTI P, MATERAZZI S: TRPA1/NOX in the soma of trigeminal ganglion neurons mediates migraine-related pain of glyceryl trinitrate in mice. Brain 141: 2312-2328, 2018. https://doi.org/10.1093/brain/awy177

MARTINEZ GQ, GORDON SE: Multimerization of Homo sapiens TRPA1 ion channel cytoplasmic domains. PLoS One 14: e0207835, 2019. https://doi.org/10.1371/journal.pone.0207835

MATTA JA, AHERN GP: Voltage is a partial activator of rat thermosensitive TRP channels. J Physiol 585: 469-482, 2007. https://doi.org/10.1113/jphysiol.2007.144287

MIYAKE T, NAKAMURA S, ZHAO M, SO K, INOUE K, NUMATA T, TAKAHASHI N, SHIRAKAWA H, MORI Y, NAKAGAWA T, KANEKO S: Cold sensitivity of TRPA1 is unveiled by the prolyl hydroxylation blockade-induced sensitization to ROS. Nat Commun 7: 12840, 2016. https://doi.org/10.1038/ncomms12840

MOPARTHI L, KICHKO TI, EBERHARDT M, HOGESTATT ED, KJELLBOM P, JOHANSON U, REEH PW, LEFFLER A, FILIPOVIC MR, ZYGMUNT PM: Human TRPA1 is a heat sensor displaying intrinsic U-shaped thermosensitivity. Sci Rep 6: 28763, 2016. https://doi.org/10.1038/srep28763

MOPARTHI L, SURVERY S, KREIR M, SIMONSEN C, KJELLBOM P, HOGESTATT ED, JOHANSON U, ZYGMUNT PM: Human TRPA1 is intrinsically cold- and chemosensitive with and without its N-terminal ankyrin repeat domain. Proc Natl Acad Sci U S A 111: 16901-16906, 2014. https://doi.org/10.1073/pnas.1412689111

NAGATOMO K, KUBO Y: Caffeine activates mouse TRPA1 channels but suppresses human TRPA1 channels. Proc Natl Acad Sci U S A 105: 17373-17378, 2008. https://doi.org/10.1073/pnas.0809769105

NASSINI R, GEES M, HARRISON S, DE SIENA G, MATERAZZI S, MORETTO N, FAILLI P, PRETI D, MARCHETTI N, CAVAZZINI A, MANCINI F, PEDRETTI P, NILIUS B, PATACCHINI R, GEPPETTI P: Oxaliplatin elicits mechanical and cold allodynia in rodents via TRPA1 receptor stimulation. Pain 152: 1621-1631, 2011. https://doi.org/10.1016/j.pain.2011.02.051

NATIVI C, GUALDANI R, DRAGONI E, DI CESARE MANNELLI L, SOSTEGNI S, NORCINI M, GABRIELLI G, LA MARCA G, RICHICHI B, FRANCESCONI O, MONCELLI MR, GHELARDINI C, ROELENS S: A TRPA1 antagonist reverts oxaliplatin-induced neuropathic pain. Sci Rep 3: 2005, 2013. https://doi.org/10.1038/srep02005

NILIUS B, TALAVERA K, OWSIANIK G, PRENEN J, DROOGMANS G, VOETS T: Gating of TRP channels: a voltage connection? J Physiol 567: 35-44, 2005. https://doi.org/10.1113/jphysiol.2005.088377

ODA M, KUBO Y, SAITOH O: Sensitivity of Takifugu TRPA1 to thermal stimulations analyzed in oocytes expression system. Neuroreport 29: 280-285, 2018. https://doi.org/10.1097/WNR.0000000000000939

ODA M, KUROGI M, KUBO Y, SAITOH O: Sensitivities of two zebrafish TRPA1 paralogs to chemical and thermal stimuli analyzed in heterologous expression systems. Chem Senses 41: 261-272, 2016. https://doi.org/10.1093/chemse/bjv091

ODA M, SAITO K, HATTA S, KUBO Y, SAITOH O: Chemical and thermal sensitivity of medaka TRPA1 analyzed in heterologous expression system. Biochem Biophys Res Commun 494: 194-201, 2017. https://doi.org/10.1016/j.bbrc.2017.10.057

PARK JH, CHAE J, ROH K, KIL EJ, LEE M, AUH CK, LEE MA, YEOM CH, LEE S: Oxaliplatin-induced peripheral neuropathy via TRPA1 stimulation in mice dorsal root ganglion is correlated with aluminum accumulation. PLoS One 10: e0124875, 2015. https://doi.org/10.1371/journal.pone.0124875

PATIL MJ, SALAS M, BIALUHIN S, BOYD JT, JESKE NA, AKOPIAN AN: Sensitization of small-diameter sensory neurons is controlled by TRPV1 and TRPA1 association. FASEB J 34: 287-302, 2020. https://doi.org/10.1096/fj.201902026R

PAULSEN CE, ARMACHE JP, GAO Y, CHENG Y, JULIUS D: Structure of the TRPA1 ion channel suggests regulatory mechanisms. Nature 520: 511-517, 2015. https://doi.org/10.1038/nature14367 
PROBER DA, ZIMMERMAN S, MYERS BR, MCDERMOTT BM JR, KIM SH, CARON S, RIHEL J, SOLNICAKREZEL L, JULIUS D, HUDSPETH AJ, SCHIER AF: Zebrafish TRPA1 channels are required for chemosensation but not for thermosensation or mechanosensory hair cell function. J Neurosci 28: 10102-10110, 2008. https://doi.org/10.1523/JNEUROSCI.2740-08.2008

SAITO S, NAKATSUKA K, TAKAHASHI K, FUKUTA N, IMAGAWA T, OHTA T, TOMINAGA M: Analysis of transient receptor potential ankyrin 1 (TRPA1) in frogs and lizards illuminates both nociceptive heat and chemical sensitivities and coexpression with TRP vanilloid 1 (TRPV1) in ancestral vertebrates. J Biol Chem 287: 30743-30754, 2012. https://doi.org/10.1074/jbc.M112.362194

SAITO S, OHKITA M, SAITO CT, TAKAHASHI K, TOMINAGA M, OHTA T: Evolution of heat sensors drove shifts in thermosensation between Xenopus species adapted to different thermal niches. J Biol Chem 291: 11446-11459, 2016. https://doi.org/10.1074/jbc.M115.702498

SAITO S, SAITO CT, NOZAWA M, TOMINAGA M: Elucidating the functional evolution of heat sensors among Xenopus species adapted to different thermal niches by ancestral sequence reconstruction. Mol Ecol 28: 3561-3571, 2019. https://doi.org/10.1111/mec.15170

SAITO S, TOMINAGA M: Evolutionary tuning of TRPA1 and TRPV1 thermal and chemical sensitivity in vertebrates. Temperature 4: 141-152, 2017. https://doi.org/10.1080/23328940.2017.1315478

SANCHEZ-MORENO A, GUEVARA-HERNANDEZ E, CONTRERAS-CERVERA R, RANGEL-YESCAS G, LADRON-DE-GUEVARA E, ROSENBAUM T, ISLAS LD: Irreversible temperature gating in trpv1 sheds light on channel activation. Elife 7: e36372, 2018. https://doi.org/10.7554/eLife.36372

SAWADA Y, HOSOKAWA H, HORI A, MATSUMURA K, KOBAYASHI S: Cold sensitivity of recombinant TRPA1 channels. Brain Res 1160: 39-46, 2007. https://doi.org/10.1016/j.brainres.2007.05.047

SINICA V, ZIMOVA L, BARVIKOVA K, MACIKOVA L, BARVIK I, VLACHOVA V: Human and mouse TRPA1 are heat and cold sensors differentially tuned by voltage. Cells 9: 57, 2019. https://doi.org/10.3390/cells9010057.

SMITH ESJ, PARK TJ, LEWIN GR: Independent evolution of pain insensitivity in African mole-rats: origins and mechanisms. J Comp Physiol A Neuroethol Sens Neural Behav Physiol 206: 313-325, 2020. https://doi.org/10.1007/s00359-020-01414-w

STARTEK JB, BOONEN B, LOPEZ-REQUENA A, TALAVERA A, ALPIZAR YA, GHOSH D, VAN RANST N, NILIUS B, VOETS T, TALAVERA K: Mouse TRPA1 function and membrane localization are modulated by direct interactions with cholesterol. Elife 8: e46084, 2019a. https://doi.org/10.7554/eLife.46084

STARTEK JB, VOETS T, TALAVERA K: To flourish or perish: evolutionary TRiPs into the sensory biology of plantherbivore interactions. Pflugers Arch 471: 213-236, 2019b. https://doi.org/10.1007/s00424-018-2205-1

STORY GM, PEIER AM, REEVE AJ, EID SR, MOSBACHER J, HRICIK TR, EARLEY TJ, HERGARDEN AC, ANDERSSON DA, HWANG SW, MCINTYRE P, JEGLA T, BEVAN S, PATAPOUTIAN A: ANKTM1, a TRP-like channel expressed in nociceptive neurons, is activated by cold temperatures. Cell 112: 819-829, 2003. https://doi.org/10.1016/S0092-8674(03)00158-2

SUO Y, WANG Z, ZUBCEVIC L, HSU AL, HE Q, BORGNIA MJ, JI RR, LEE SY: Structural insights into electrophile irritant sensing by the human TRPA1 channel. Neuron 105: 882-894 e885, 2020. https://doi.org/10.1016/j.neuron.2019.11.023

SURVERY S, MOPARTHI L, KJELLBOM P, HOGESTATT ED, ZYGMUNT PM, JOHANSON U: The N-terminal ankyrin repeat domain is not required for electrophile and heat activation of the purified mosquito TRPA1 receptor. J Biol Chem 291: 26899-26912, 2016. https://doi.org/10.1074/jbc.M116.743443

TAKAHASHI N, KUWAKI T, KIYONAKA S, NUMATA T, KOZAI D, MIZUNO Y, YAMAMOTO S, NAITO S, KNEVELS E, CARMELIET P, OGA T, KANEKO S, SUGA S, NOKAMI T, YOSHIDA J, MORI Y: TRPA1 underlies a sensing mechanism for O2. Nat Chem Biol 7: 701-711, 2011. https://doi.org/10.1038/nchembio.640

TALAVERA K, GEES M, KARASHIMA Y, MESEGUER VM, VANOIRBEEK JA, DAMANN N, EVERAERTS W, BENOIT M, JANSSENS A, VENNEKENS R, VIANA F, NEMERY B, NILIUS B, VOETS T: Nicotine activates the chemosensory cation channel TRPA1. Nat Neurosci 12: 1293-1299, 2009. https://doi.org/10.1038/nn.2379

TALAVERA K, STARTEK JB, ALVAREZ-COLLAZO J, BOONEN B, ALPIZAR YA, SANCHEZ A, NAERT R, NILIUS B: Mammalian transient receptor potential TRPA1 channels: From structure to disease. Physiol Rev 100: 725-803, 2020. https://doi.org/10.1152/physrev.00005.2019 
TERRETT JA, CHEN H, SHORE DG, VILLEMURE E, LAROUCHE-GAUTHIER R, DERY M, BEAUMIER F, CONSTANTINEAU-FORGET L, GRAND-MAITRE C, LEPISSIER L, CIBLAT S, STURINO C, CHEN Y, HU B, LU A, WANG Y, CRIDLAND AP, WARD SI, HACKOS DH, REESE RM, ET AL.: Tetrahydrofuranbased transient receptor potential ankyrin 1 (TRPA1) antagonists: Ligand-based discovery, activity in a rodent asthma model, and mechanism-of-action via cryogenic electron microscopy. J Med Chem 64: 3843-3869, 2021. https://doi.org/10.1021/acs.jmedchem.0c02023

TU N, LIANG D, ZHANG P: Whole-exome sequencing and genome-wide evolutionary analyses identify novel candidate genes associated with infrared perception in pit vipers. Sci Rep 10: 13033, 2020. https://doi.org/10.1038/s41598-020-69843-w

VANDEWAUW I, De CLERCQ K, MULIER M, HELD K, PINTO S, VAN RANST N, SEGAL A, VOet T, VENNEKENS R, ZIMMERMANN K, VRIENS J, VOETS T: A TRP channel trio mediates acute noxious heat sensing. Nature 555: 662-666, 2018. https://doi.org/10.1038/nature26137

VIANA F: TRPA1 channels: molecular sentinels of cellular stress and tissue damage. J Physiol 594: 4151-4169, 2016. https://doi.org/10.1113/JP270935

VON NIEDERHAUSERN V, KASTENHUBER E, STAUBLE A, GESEMANN M, NEUHAUSS SC: Phylogeny and expression of canonical transient receptor potential (TRPC) genes in developing zebrafish. Dev Dyn 242: 1427-1441, 2013. https://doi.org/10.1002/dvdy.24041

WAN X, LU Y, CHEN X, XIONG J, ZHOU Y, LI P, XIA B, LI M, ZHU MX, GAO Z: Bimodal voltage dependence of TRPA1: mutations of a key pore helix residue reveal strong intrinsic voltage-dependent inactivation. Pflugers Arch 466: 1273-1287, 2014. https://doi.org/10.1007/s00424-013-1345-6

WANG H, SCHUPP M, ZURBORG S, HEPPENSTALL PA: Residues in the pore region of Drosophila transient receptor potential A1 dictate sensitivity to thermal stimuli. J Physiol 591: 185-201, 2013. https://doi.org/10.1113/jphysiol.2012.242842

WANG S, LEE J, RO JY, CHUNG MK: Warmth suppresses and desensitizes damage-sensing ion channel TRPA1. Mol Pain 8: 22, 2012. https://doi.org/10.1186/1744-8069-8-22

WEI H, CHAPMAN H, SAARNILEHTO M, KUOKKANEN K, KOIVISTO A, PERTOVAARA A: Roles of cutaneous versus spinal TRPA1 channels in mechanical hypersensitivity in the diabetic or mustard oil-treated non-diabetic rat. Neuropharmacology 58: 578-584, 2010. https://doi.org/10.1016/j.neuropharm.2009.12.001

WILSON SR, NELSON AM, BATIA L, MORITA T, ESTANDIAN D, OWENS DM, LUMPKIN EA, BAUTISTA DM: The ion channel TRPA1 is required for chronic itch. J Neurosci 33: 9283-9294, 2013. https://doi.org/10.1523/JNEUROSCI.5318-12.2013

WINTER Z, GRUSCHWITZ P, EGER S, TOUSKA F, ZIMMERMANN K: Cold temperature encoding by cutaneous TRPA1 and TRPM8-carrying fibers in the mouse. Front Mol Neurosci 10: 209, 2017. https://doi.org/10.3389/fnmol.2017.00209

WITSCHAS K, JOBIN ML, KORKUT DN, VLADAN MM, SALGADO G, LECOMTE S, VLACHOVA V, ALVES ID: Interaction of a peptide derived from C-terminus of human TRPA1 channel with model membranes mimicking the inner leaflet of the plasma membrane. Biochim Biophys Acta 1848: 1147-1156, 2015. https://doi.org/10.1016/j.bbamem.2015.02.003

XIAO B, DUBIN AE, BURSULAYA B, VISWANATH V, JEGLA TJ, PATAPOUTIAN A: Identification of transmembrane domain 5 as a critical molecular determinant of menthol sensitivity in mammalian TRPA1 channels. J Neurosci 28: 9640-9651, 2008. https://doi.org/10.1523/JNEUROSCI.2772-08.2008

YAMAKI S, CHAU A, GONZALES L, MCKEMY DD: Nociceptive afferent phenotyping reveals that transient receptor potential ankyrin 1 promotes cold pain through neurogenic inflammation upstream of the neurotrophic factor receptor GFRalpha3 and the menthol receptor transient receptor potential melastatin 8. Pain 162: 609-618, 2020. https://doi.org/10.1097/j.pain.0000000000002043

YIN Y, LE SC, HSU AL, BORGNIA MJ, YANG H, LEE SY: Structural basis of cooling agent and lipid sensing by the cold-activated TRPM8 channel. Science 363: eaav9334, 2019. https://doi.org/10.1126/science.aav9334

ZHANG Z, TOTH B, SZOLLOSI A, CHEN J, CSANADY L: Structure of a TRPM2 channel in complex with Ca(2+) explains unique gating regulation. Elife 7: e36409, 2018. https://doi.org/10.7554/eLife.36409 
ZHAO J, LIN KING JV, PAULSEN CE, CHENG Y, JULIUS D: Irritant-evoked activation and calcium modulation of the TRPA1 receptor. Nature 585: 141-145, 2020. https://doi.org/10.1038/s41586-020-2480-9

ZHONG L, BELLEMER A, YAN H, KEN H, JESSICA R, HWANG RY, PITT GS, TRACEY WD: Thermosensory and nonthermosensory isoforms of Drosophila melanogaster TRPA1 reveal heat-sensor domains of a thermoTRP Channel. Cell Rep 1: 43-55, 2012. https://doi.org/10.1016/j.celrep.2011.11.002

ZHOU Y, SUZUKI Y, UCHIDA K, TOMINAGA M: Identification of a splice variant of mouse TRPA1 that regulates TRPA1 activity. Nat Commun 4: 2399, 2013. https://doi.org/10.1038/ncomms3399

ZIMA V, WITSCHAS K, HYNKOVA A, ZIMOVA L, BARVIK I, VLACHOVA V: Structural modeling and patchclamp analysis of pain-related mutation TRPA1-N855S reveal inter-subunit salt bridges stabilizing the channel open state. Neuropharmacology 93: 294-307, 2015. https://doi.org/10.1016/j.neuropharm.2015.02.018

ZIMOVA L, BARVIKOVA K, MACIKOVA L, VYKLICKA L, SINICA V, BARVIK I, VLACHOVA V: Proximal C-terminus serves as a signaling hub for TRPA1 channel regulation via its interacting molecules and supramolecular complexes. Front Physiol 11: 189, 2020. https://doi.org/10.3389/fphys.2020.00189

ZIMOVA L, SINICA V, KADKOVA A, VYKLICKA L, ZIMA V, BARVIK I, VLACHOVA V: Intracellular cavity of sensor domain controls allosteric gating of TRPA1 channel. Sci Signal 11: eaan8621, 2018. https://doi.org/10.1126/scisignal.aan8621 